\title{
"Projectification" of the Firm,
}

\author{
the Renault Case ${ }^{2}$
}

Christophe Midler

\begin{abstract}
Many industrial firms are implementing fundamental changes in their organizations to increase the efficiency of their product development processes. Here we focus on the relations between project management models and the permanent organization and processes of the firm.

The case of the French firm Renault is being studied. This firm implemented a transition, from a classical funtional organization in the 1960's to project coordination in the 1970's and autonomous and powerful project teams since 1989. Such advanced project management has deep and destabilising effects on the other permanent logics of the firm (task definitions, hierarchic regulations, carrier management, functions and suppliers relationship). Therefore a phase of "projectification" is now under way to adapt these permanent processes to the new context.
\end{abstract}

Key words: project management, organization, organizational learning, automobile industry.

\footnotetext{
${ }^{2}$ Article paru dans Scandinavian Journal of Management, vol 11, n, pp363-375, 1995.
} 


\section{Project Management and Evolution of the Permanent Organization of the Firm}

Many companies in the Western world are currently implementing far-reaching reforms of their management systems for new products. This trend is affecting different sectors (Clark et al 1992, Giard and Midler 1993) and in it can be seen the effects of a shift from the competitive modes of a mass-market economy to those of an economy typified by variety or reactive adaptability. In this type of context the competitive edge of any company depends firstly on its capacity to market genuinely innovative products rapidly and at satisfactory levels of quality and pricing — and secondly on targeting them at specific market niches, with the aim of outmoding more ordinary products (Dertouzos et al 1990; Stalk and Hout, 1990; Cohendet and Lléréna 1992; Coriat and Taddéi 1993). The combination of these strategies multiplies the number of projects to be managed.

The automobile sector demonstrates a particularly good example of the trend (Clark and Fujimoto 1991, Midler 1993a). It typified mass-market industry up to the 1960s, and is now at the forefront of the developments in concurrent engineering and integrated project teams.

We will focus our analysis of such transitions on the relations between the temporary project organizations and practices on one side, and the permanent organizations and processes of the firm on the other. Galbraith (1971) analysed the range of alternatives between a functional organization and a product (or project) organization, the median situation being the matrix organization. Focus was there essentially on formal organizational patterns. More recent works in organizations give more precise and varied models for the permanent coordination processes within the firms (see Mintzberg 1979). Comparative research between American and Japaneese firms demonstrate the influence of such characteristics of permanent coordination processes on the project practices and efficiency (Aoki 1990, Clark et al 1987, Clark and Fujimoto 1991). Navarre (1993, p 181, 215) formalised the relation between the project management paradigm and the characterization of the firm: The classical north American project management paradigm is related to a vertical type of firm as the modern concurrent and integrated approches are related to a horizontal type of organizations. This research domain is actually growing, and it is also appearing under new labels as "management by projects" or the "Project-oriented Company" (Gareis 1989).

We aspire here to make an empirical contribution to such an analysis of relations between project management and firm organization. The article contains a case study, the "projectification" of the French firm Renault, during a four phase transition from the 1960s to ongoing evolutions. We will try to associate a political approach of the change (what is the 
power and the autonomy of project teams within the firm ?) with a learning perspective (Argyris and Schön, 1978).

The account is based on longitudinal research which associates different methodologies: historical analysis, ex-post project diagnostics in the 1980's and real-time analysis of Renault Twingo project from 1989 to 1993 (Midler 1993a).

First Phase: Functional Organization and Informal Project Coordination in the 1960's

In the 1960 's, Renault had a typical functional organization. It was divided, as shown in figure 1, into powerful, compartmentalized skill-based departments: engineering design, methods, production and so forth. No direct link existed between the operational divisions.

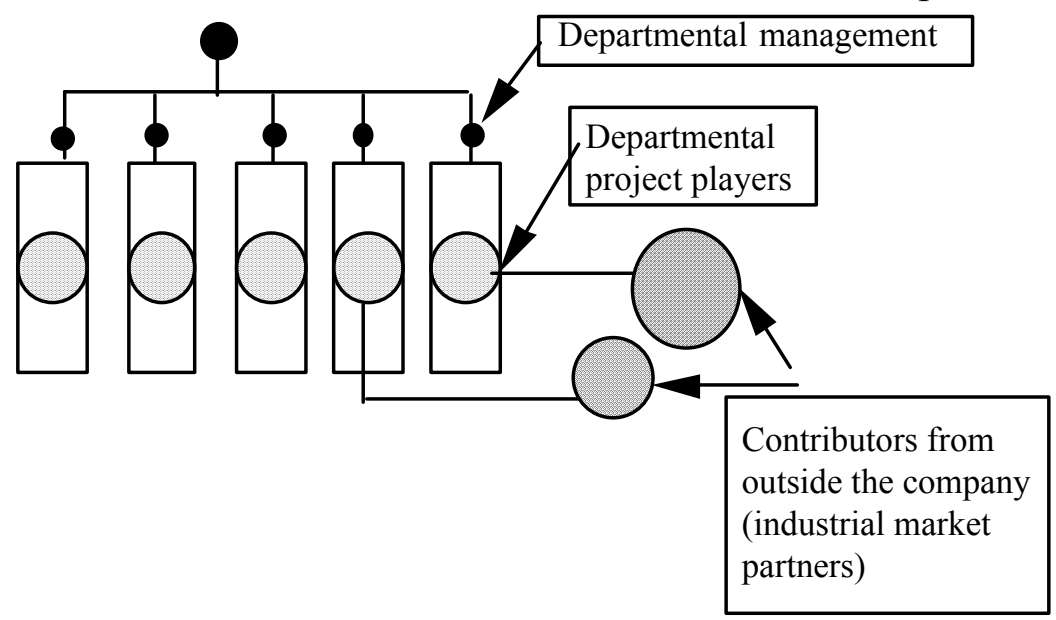

Figure 1: The Functional Structure

(adapted from Clark, Hayes and Wheelwright, 1988)

Therefore, in the 1960s there was a time of informal project coordination [artisanat projet in French as used by Pierre Dreyfus, Renault CEO (Dreyfus, 1977)]. Each project was managed on a case-by-case basis. The only person who linked and arbitrated between them was the CEO himself. This approach was suited to the manufacture of few non-diversified products but by the 1970s it was no longer capable of dealing with the growth of products in terms of number and complexity .

\section{Second Phase: Centralized Project Coordination from 1970 to 1988.}

The beginning of 1970 marked a first important evolution in new product development management. Project management and marketing experts were recruited, especially from American firms which had already experimented with these techniques. Organizational 
structures cutting horizontally across the corporation were set up as seen in figure 2, involving the heads of the various operational divisions. These met in committees to look at the project-related problems. Apart from these committees, communication remained essentially vertical, between the top and the bottom of each functional department. Project coordinators were appointed: these were people whose corporate status was fairly low and whose competence was not yet fully confirmed. Their task was to gather information for the committees of departmental managers and they obviously possessed no decision-making powers.

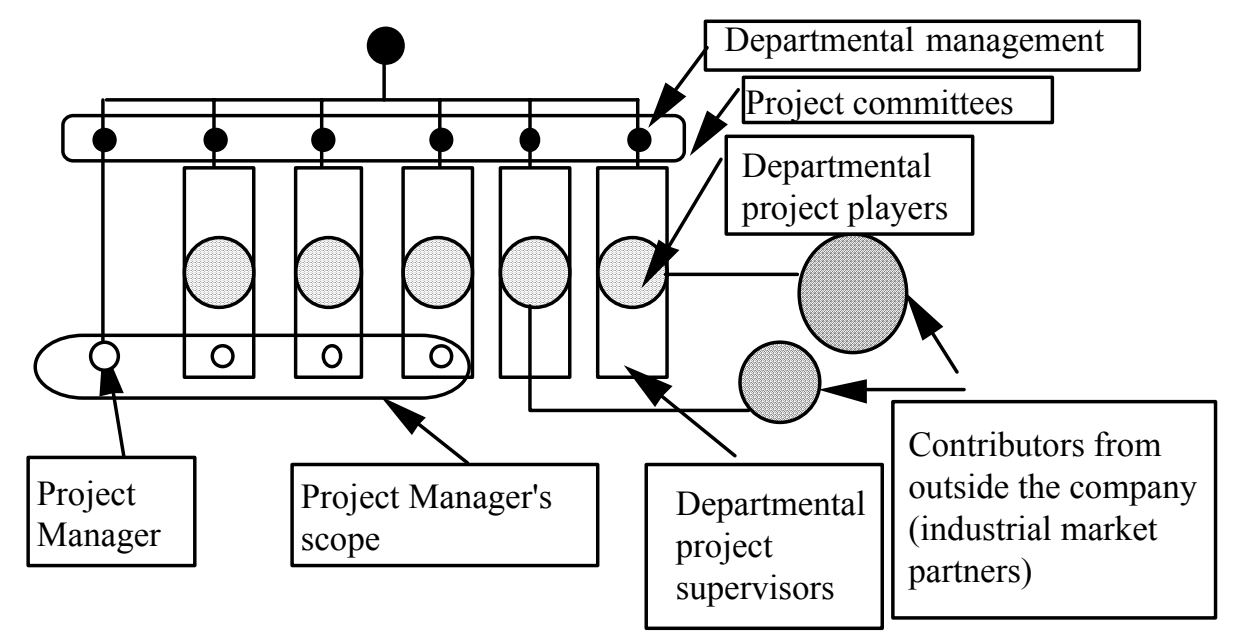

Figure 2: The Project Coordination Structure (adapted from Clark, Hayes and Wheelwright, 1988)

Project control techniques were implemented at that time. A general standard product development planning was set to coordinate the different contributions. A common economic language based on the project Return On Investment [Taux de Rendement Interne] concept was defined, to arbitrate trade-offs between the various corporate departments.

In this first step of "projectification" of the firm, the processes involved only the top of the firm. Its focus was essentially to manage the project portfolio in a way that would be coherent with the global strategy of the firm. Another important point is that the projects have no champion to enforce their identity and negociate with the strategies of the skill-based departments. The project is a result, a compromise between existing professional goals and methodologies. Finally, this phase is oriented towards implementation of the standard Project Management tools: planning, budgeting and the ROI criterion.

In the middle of the 1980's, this Project Coordination System failed to meet Renault's increasing ambitions in terms of time, quality and cost control of the projects (Midler 1993a p 99). Matching the skill-based department strategies and contributions without a powerful coordinator was a particularly difficult and little effective process. In the same time, international comparison revealed more generally occidental project management practices to be far less competitive than Japanese automobile product development processes (Clark et al 1987). 
Third Phase: Empowerment and Autonomy of the Project Management Structure in 1989

These facts were already known by 1986-1987. But Renault was then in an important crisis and all concerns and energies were focussed on short term programs in order to improve the financial situation of the firm. Developing project management performance was not a priority in that context. As soon as short term profitability objectives were met, the new CEO, Raymond H. Lévy introduced in December 1988 a reform creating Project Directors.

This change was essentially a political move: The innovation was not in the project management structure (it existed since the early 1970's) nor in a new methodology but in the power and autonomy given to this role. Project managers have now a powerful formal position in the firm, giving the project strong enough status to carry on an equally-matched dialogue with top departmental echelons. The project management role was entrusted to experienced and successful executive personnel, with much influence capacities due to their prestige and know-how. The project structure surrounding the Project Director was also developed to a complete team of departmental project supervisors (products, engineering, industrial production, purchasing, sales, quality, planning controler, economic controler, personnel relations) with one foot in each hierarchy and operating within a matrix-type model (Galbraith, 1971). Figure 3 illustrates such a Project Director organizational form.

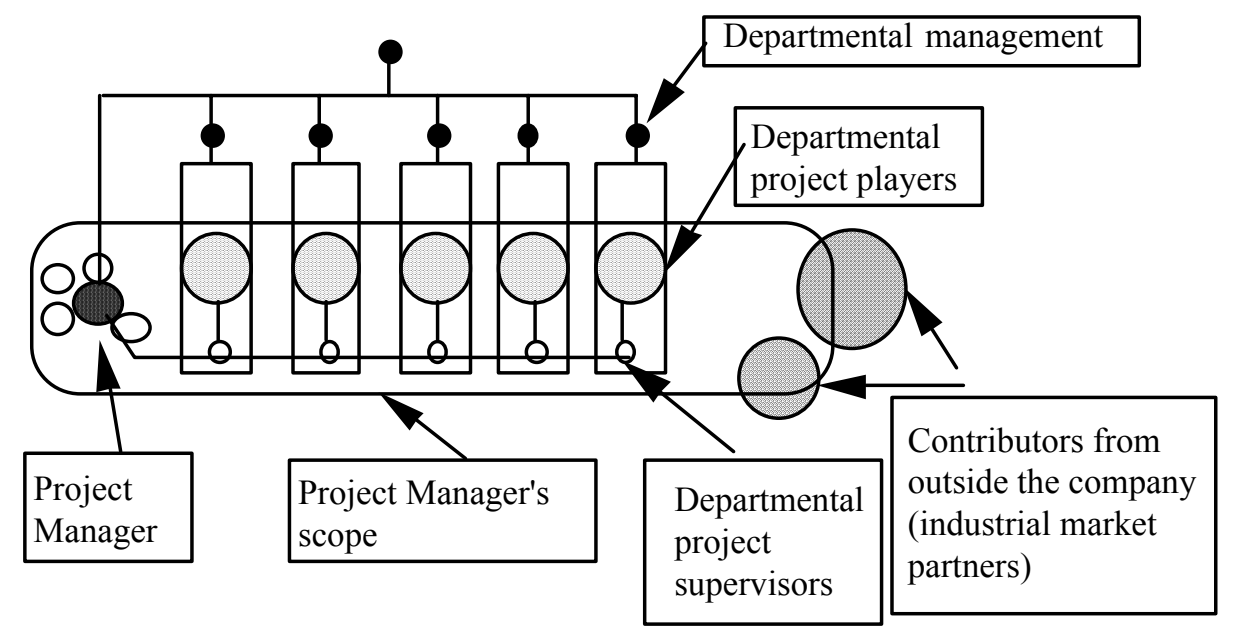

Figure 3: The Project Director Structure (adapted from Clark, Hayes and Wheelwright, 1988)

\section{Characterization of the Project Management Practices}

This structural change is only the most visible part of the changing process; the part that was much studied after Chandler presented his famous theory of adjustment of structure to 
strategy (1962). Organizational change analysis needs also to focus on practices, behaviours and know-how within the formal patterns. The development of a new car involves more than a thousand professionals, hundreds of different firms. These complexe cooperative processes cannot be changed in an instant by the creation of a new project structure. Therefore, after the structural change in December 1988 began a experimental period for project management within Renault, to try to turn the new autonomy into effective practices for development of the new products. The first project of this third phase was the Twingo project which began in january 1989. We had the opportunity of studying it with a real-time observation methodology from its beginning to its end. This research followed another one, were we had made an ex-post analysis of a project of the beginning of the 1980s, ruled in the coordination project manager form.

The conclusions of that research (Midler 1993a) can be interpreted in Argyris and Schön terms of level of learning (Argyris and Schön 1978). The transition from phase one to phase two was a single loop learning process: A better coordination in a stable frame of reference. But the transition from the second phase to the third must be seen as a double loop learning process. We have pointed out five instances as radical changes in the "theories in use" of the firm concerning the product development processes.

\section{The Global and Entrepreneurial Responsability of the Project Role}

The first deep change lies in the definition of project roles. The job is defined by a result responsability on a global goal, the success of the future car, without mentioning required skills, expertise or methodology. It is an entrepreneurial job definition, with a great autonomy on the means to achieve the target, as projects managers in the precedent phase were characterized as applicant of the standard development procedures of the firm.

The Twingo project was a spectacular experiment to demonstrate how such autonomy could be used to create the organizational context that could drive all energies and concerns to the very key problems of a specific project.

One important point about this project, a little innovative urban car, was the economic constraint. Many other similar project had already failed at Renault since 1973 on that criteria. Therefore, the project team generalised a "design to cost" methodology which reversed the classical development process. The development process was initiated on the base of volontarist economic targets for each sub-system of the car and piece of the manufacturing system, targets which were consistent with the global objective of the program. Then, the devopment went on to find technical solutions to fit these initial economic constraints.

Such a process was found to be particularly efficient (see Midler, 1993a, p26-33). It led to significative changes in the manufacturing process (the first technology scenarios included a high degree of sophisticated and expensive automation, the design-to-cost operation leading to a $30 \%$ cut in the body shop investment for example) as on basic components as important 
as the motor (the investment cost of the motor finally chosen for the Twingo was less than half of the investment needed with the first motor proposition made by the motor engineers of the firm). On the sales side, the work done by project management led to innovations in distribution modes and in communications; these in turn led to major savings in program costs.

\section{The Importance of Singularities in Projects}

The classical industrial rationality is in a certain way a general attempt to escape from the singularities of particular situations. Professionnal identities are definied on typified problems. They implement standard operating procedures (Cyert and March 1963). They introduce "buffers" and rules to disconnect these logics from outside contingencies (Thompson 1967).

But singularities are key points for projects, these "one shot" adventures which cannot be cut from their specific context. Empowered project managers are therefore constant advocates for tailor-made methodologies and solutions for the particular problems of their project. A lot of decision on the Twingo project can be interpreted as a effort to make the most of the pecularities of the product : the innovative concept and design of the car, the simplicity of an undiversified product, etc... One exemple of such a decision was the modification of the planning of the project to meet the opportunity of a presentation of the car at the "Mondial de l'Automobile" in Paris in October of 1992.

\section{Systematization of Horizontal Communication between Professionnals}

In the second phase of Renault "projectification" process, cross-professionnal dialogue was limited to the top of the firm. In the third phase cross-professionnal communication had been generalised to the bottom of the firm, in order to anticipate possible problems as to improve the trade-offs between the various logical systems involved.

This horizontal coordination was implemented in the project scheduling. Formerly, the work of the various experts was performed sequentially, starting with marketing and design, going on to engineering, production methods, materials purchasing and serial production and ending up with sales. On the Twingo project, contributors traditionally playing "downstream" roles (plant personnel, outside suppliers, sales personnel) were involved right from the beginning.

The cross-professional communication was also concretized by physically gathering together a large proportion of expert personnel in the same location - known as the "project platform" [plateau du projet in French] — with the physical media and tools for development near at hand. Formerly, workers on a project stayed where their departments were physically located, which often meant that they were far apart. Physical proximity therefore enabled time measured in weeks to be saved in solving interface problems, in particular the management of modifications dictated by industrial feasibility. 
Finally, a new project guidance structure was set up with the goal of decentralizing the control of costs, schedules and quality risks out to those contributing directly to project development. To achieve this, the project was broken down into some two dozen sub-projects based on physical sub-assemblies or specific client services (automobile noise and behavior studies for instance). In each of these sub-projects, a group was formed to represent each of the skills involved: engineering, methods, purchasing, outside suppliers, industrial production etc. This decentralization made it possible to mobilize effectively the project players involved at ground level to achieve project objectives and make major improvements in the quality of the decisions reached. Members of the project team ensured the overall coherence of the work done by the various sub-groups.

\section{Project Temporality and Convergence Logic}

One of the major changes implied by the development processes introduced by project teams was to bind the corporation to a specific temporal progression, a progression defined by the project itself. In traditional development processes each department contributes to the overall project at a given point in the sequence, working toward a limited horizon. Now all contributors work within a common time frame (Sayles and Chandler 1971), which we have modelled in a diagram represented in Figure 4 (Midler 1993a, p 98).
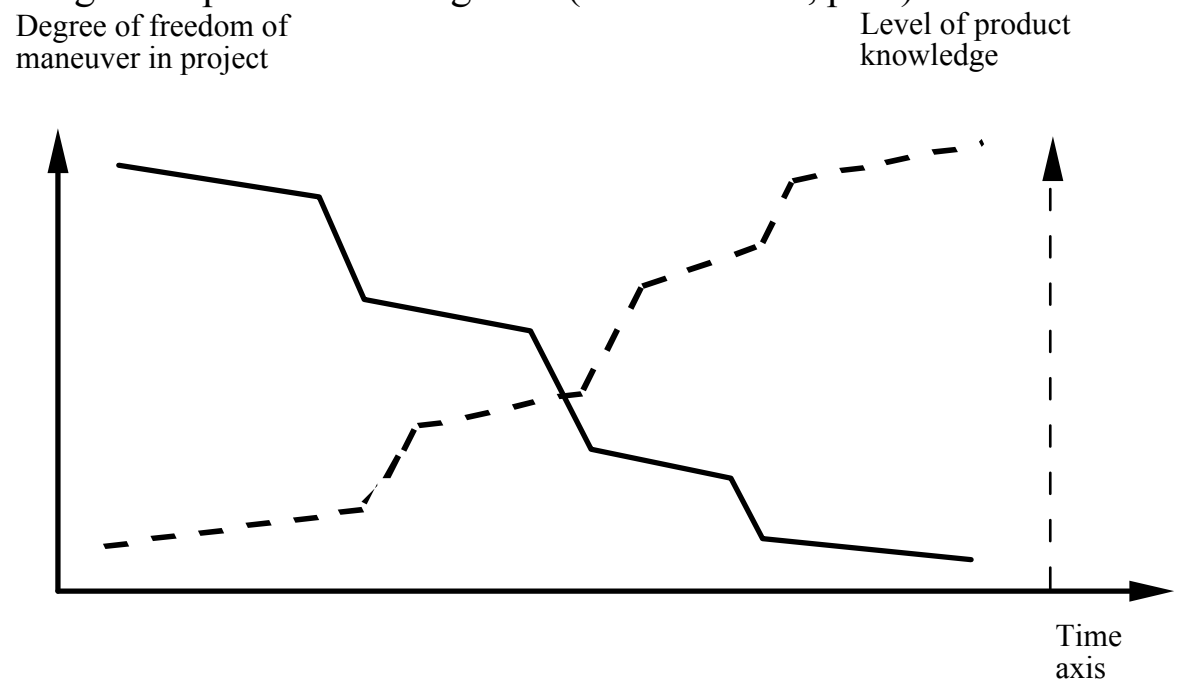

Figure 4: Project Convergence (from Midler, 1993)

In this model, a project is represented by two connected processes: A learning process (dotted line) in which uncertainty about product features, industrial feasibility and market reception is gradually reduced, and a work process (solid line) in which the freedom to change the project is gradually reduced as the degree of irreversibility of project decisions rises. Project management has to control these coupled processes from the upstream initiation phase, where virtually anything is possible — but where nothing is actually known for sure - to the phase downstream when everything is known, but virtually no free choices remain.

The anticipation strategies in the modern concurrent engineering approach can be visualised as in figure 5. In a first phase, project managers try to prevent early commitment in heavy irreversible decisions in the same time as they try to gather as much information as possible 
on the project. On a second phase, the project is locked as precisely and exhaustively as possible, for modern industrial systems are so integrated that their different variables are closely dependant. Finally, at the end of the project speed and rapid reaction are given maximum priority in order to expedite the finding of solutions to the remaining technical obstacles.

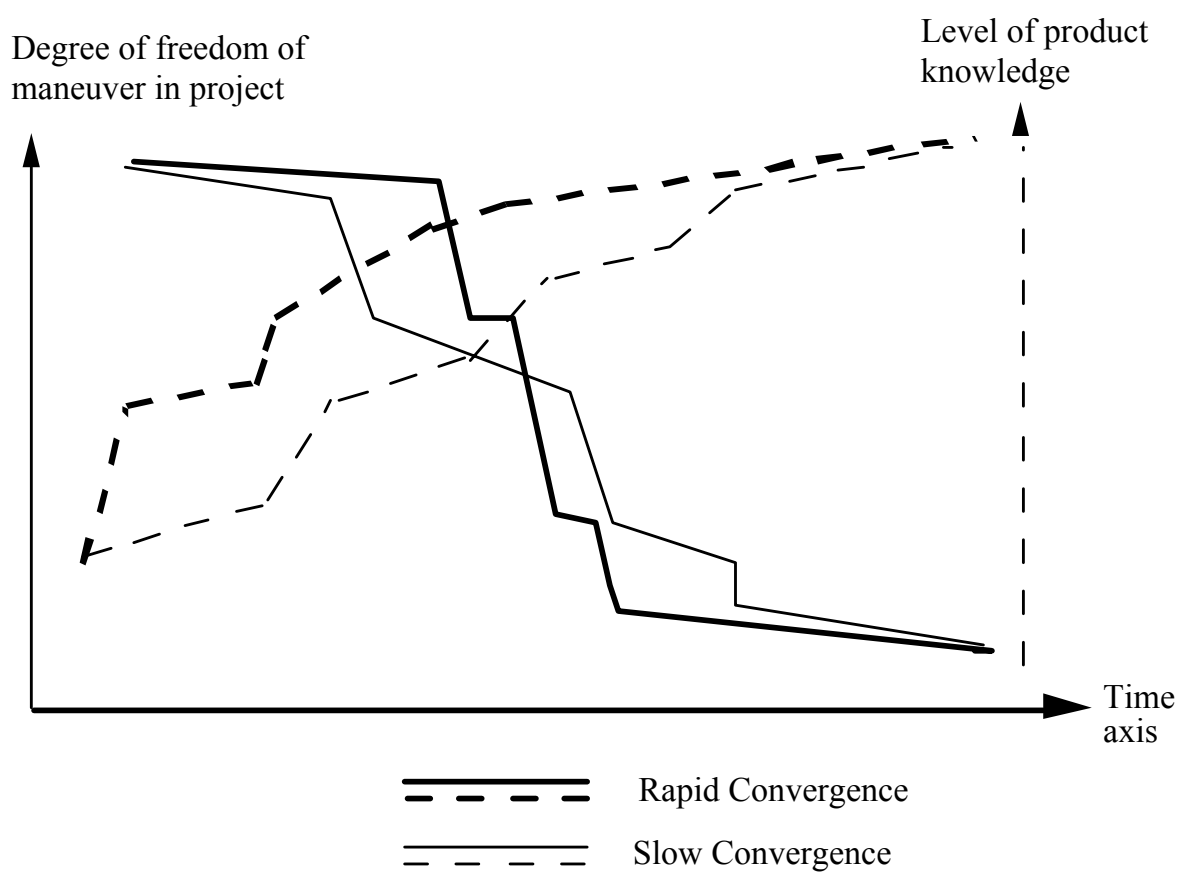

Figure 5: Accelerating the project cycle

This focus-down convergence logic leads to joint continuity and rapid adaptation in management styles on the project (Midler, 1993b). On one hand, learning needs memory process in the project team. If those involved at the end of the process were not there at the beginning, there is a strong likelihood that they will have no understanding of the compromises and trade-offs negotiated by others. They will not accurately assess the risks taken by others in full awareness of the context, and there is even a risk that they will not feel personally bound by commitments entered into by others. But on the other hand, the management capacities needed at each phase are very different : the emerging phase needs strategic insights, creativity and charisma, a capacity to sustain high uncertainty contexts; the control phase requires precision, realism and negociation talents; the last phase is a permanent race against time, where remaining "details" can stop the process if they are not taken care of rapidly and where the project team have to undergo a very conflictual context.

The Twingo project was typical of such a focus-down convergence logic. When the project team was formed, no decision had been taken to go ahead with the project. At that time it still seemed impossibly risky in economic terms : $15 \%$ reduction in variable costs and $25 \%$ in investment were needed to meet the ROI target. Project managers then capitalized on the risk 
of abandonment of the project to look at any route which had not really been explored up to that time. Studies went on for more than a year before the decision to build the automobile was finally taken, based on satisfying data. When this point of no return had been reached, it went into a second "control" phase in which maximum stabilization was sought for all development parameters. Finally, at the end of the project speed and rapid reaction were given maximum priority in order to expedite the finding of solutions to the remaining technical obstacles. The final result were consistant with the commitment taken at the point of no return (Midler, 1993a, p50-51).

\section{$\underline{\text { Partnership Development }}$}

The introduction of concurrent engineering principles into relationships with suppliers took the form of co-development processes. Early selection of suppliers was carried out using contract specifications which were sufficiently open to enable suppliers to help in the search for solutions. The Project Manager polled equipment suppliers as early as the beginning of 1989 using component price targets as a basis. The technical solutions they submitted in response were then negotiated with engineering design personnel following a route which is exactly the opposite of what is normal; that is, purchasing personnel normally use detailed and unchangeable technical specifications to call for competitive bids from suppliers, the goal being to arrive at the best possible price (see Womack et al 1990).

Following this, the chosen equipment suppliers were closely integrated into the project development teams working inside the company in order to make quality cost and time savings in dealing with the many questions related to the interfacing of the areas for which suppliers were responsible with closely connected or interdependent project areas.

The implementation of these new procedures was to have a dramatic effect on the Twingo project: it enabled a reduction in costs of $18 \%$ to be made on the components in the design-tocost program (compared with initial estimates made by project costing personnel). Reductions on certain components even reached $30 \%$ without affecting either quality or profit margin, simply by better targeting of specifications following a complete functional analysis of the product.

The project management teams made major contributions to this evolution since their responsibilities cut right across boundaries between the corporation and the outside world: they spoke for instance in terms of "internal" and "external" suppliers, placing Renault plants and the facilities of Renault suppliers in a peer-to-peer relationship; they helped promote competition between engineering design personnel within Renault and like departments in outside equipment supply firms with the objective of widening the search for technical solutions, and so on. Purchasing personnel were naturally right at the heart of this revolution in the relationship between the corporation and its partners, a fact which implied an updating of both its supplier relations and its contacts with internal technical personnel, providing new 
meanings and new tools for traditional notions such as supplier quotation requests, selection and monitoring.

\section{The Forth Phase of Renault's Projectification: Transforming the Permanent Processes of the Firm}

Above-mentioned organizations and project management principles are now implemented on every new project within Renault. But yet, it is not the end of Renault's "projectification" process. A number of problems still remain. Professionals trained for years in a compartmentalized corporate environment have not been prepared for inter-department, or even inter-company, dialogue. Empowerment and growth of project structures lead to classical but important questions: what is the future for skill-based functional departments of the firm ? Are they going to disappear, scattered into different project teams? How is it possible to keep the long-term technical learning process, when organizational structures focusses energies on more short-term and product oriented objectives?

What therefore is the future route of the improvement process in project performances? There seem today to be two likely candidates.

- The first candidate is to continue to reinforce the importance of project structures. If this was to happen, there would be increasing development in size and responsability of project teams, skilled-based departments becoming simply labor pools on which project managers could draw.

- The route down which Renault has gone - the second candidate - is not this one. Renault has chosen to balance out strong project identities and strong departmental identities, setting up a complementary relationship between the two. As the project logic, the logic specific to technical skill departments cannot be ignored in the context of the automobile industry: maintaining and developing a sales network, increasing the productivity of a multi-product fabrication system and the level of the technical skills of engineering design personnel are objectives which are just as crucial as the success of any project. The raw material of future projects depends on the development of departmental expertise. It therefore seems to be a more efficient solution to strengthen the two complementary identities and to enhance the cooperation between them.

Against this background, the developments now to be expected are no longer so much in relation to project team management or even at the project/department interface. Rather, further "projectification" will occur in learning and internal reorganizing of corporate departments or supplier companies.

\section{Changes in the Technical Skills within Corporate Departments}


The Taylor type work division has had the effect of making some personnel specialize upstream and others downstream in a linear process. The "upstream culture" thus became habituated to abstraction, developing the capability for strategic reasoning (in other words, defining scenarios and constraints in situations with high levels of freedom of maneuver). "Downstream culture" became reactive in outlook (capable of reacting in situations in which freedom is restricted but uncertainty comparatively low), aware of the importance of detail, of the approximate character of both forecasts and theoretical presentations, and habituated to pragmatic reasoning.

Putting these two corporate cultures, as different as they are complementary, together in a context of concurrent engineering without any preparation cannot be immediately effective. The dialogue between very different departmental skill areas requires that each must show a higher capability for rationalization than in communicating with players on their own team. This requires suitable communication tools to be developed. How can it be possible, for example, to have meaningful discussions on the industrial feasibility of a component with only drawings as reference? New modes of individual knowledge and team action, in addition to new media for communication between skill-based departments, need therefore to be invented.

A further major change is the integration of technical skills and value-control expertise: in other words - controlling costs, scheduling and quality. The process whereby work was divided up led previously to a sharp separation of these two types of competences, which was harmful to projects. What a project manager wants a technician to do, for instance, is to fit his technical decisions to quality and cost targets, to work not toward technical sophistication for its own sake, but toward the final success of the project as a whole.

The final project debriefings operated as revealing the degree of expertise and relevance of skilled-based departments and pointed out the need for developping new knowledges. One spectacular evolution within Renault is the recent decision to merge the product engineering department and the process engineering department under same location and responsability, in order to develop technical knowledge combining product and process expertises. Another area for deep professional reorientation is the purchasing departments. New co-development strategies with suppliers necessitates new ways to evaluate, select and coordinate the suppliers, compared to the classical buying practices. Reengineering of buying departments is currently one of the main field of transformation, and it is not by chance that the new Director just appointed this year for conducting this transition is an outgoing Project Director.

\section{Changes in the Relationship between Departmental Management Echelons}

If horizontally-based project groups, bringing together personnel from workshops, engineering offices, purchasing departments and so on, are to function properly, those who take part in them need sufficient levels of competence and decision-making power, and they particularly need to be able to undertake negotiations which will commit their departments (and therefore the managers of those departments). 
This is incompatible with the Taylorian type of organization in which delegation is unheard of and in which competence is strictly divided between high-echelon experts and those who carry out the orders. Such organizational principles are still frequently encountered, and not only in industrial plants.

\section{Changes in Tools for Assessing Departmental Performance}

The standards by which the performance of project contributors is assessed also need to be reinvented; it is an illusion to think that project players will seek to optimize global project criteria if they are themselves assessed in isolation on criteria only partly related to their work. The upstream involvement of plants in the project is a typical example of this: the evaluation of the performance of individual plants is arrived at essentially on the basis of the ratio of the number of plant personnel to the number of automobiles produced. The involvement of workshop foremen or technicians prior to the launch of a new model, hiring and training the manufacturing team six months to a year before serial production - none of this is reflected immediately in any productivity indicator. This explains why it is so difficult to mobilize high levels of energy just at the moment when it would be most effective for the final design of facilities and the preparation of the teams involved.

\section{$\underline{\text { Changes in Relative Status between Different Functions }}$}

In Western technically advanced corporations as automobile firms, upstream technical and strategic departments used to be in a dominating position (a push forward hierarchy). Concurrent engineering and project managers concern about global compromise on the project tend to change this relationship between the different functions of the firm (towards a more "pull" hierarchy). It gives downstream people new opportunities to express and enforce their constraints and value adding rationality.

\section{$\underline{\text { Changes in Career Management within Permanent Structures }}$}

Projects are historic and temporary activities. One difficult problem is to match the continuous but temporary involvment in the project teams with the career management constraints in the permanent structures. We already saw how people rotation had dysfunctional effects on project convergence. But this rotation is generally the direct consequence of rational allocating of scarce expertise among different projects. Team dismantling at the end of a development is also a difficult problem: Permanent structures or new projects rarely open satisfactory job opportunities at the right moment.

Changes in the System of Industrial Equipment Supply and the Professionalism of Corporate $\underline{\text { Buyers }}$

The traditional attitude of the corporate buyer is to seek out the cheapest sub-contractor to make a component carefully defined by drawings and specifications. The result of this is a 
fragmentation of sub-contact work: taking stamping as an example, there are sub-contractors supplying serial production tooling, others for the first wave of prototypes, and yet others for second wave. The cheapest suppliers are often those who have made the greatest reductions in their overheads - and, by the same token, in their design costs. Modern project managers challenge the worth of this kind of narrow specialization. They are looking for partners capable of undertaking an entire development process from the first prototypes right through to serial production, with the objective of anticipating as early as possible the constraints which will exist for industrial-scale manufacture and ensuring the lessons learned upstream will be remembered downstream. It will readily be understood that this implies fundamental changes in the way in which equipment suppliers are organized (Banville and Chanaron, 1991).

\section{Conclusions for research.}

We shall conclude our analysis of the Renault journey towards project orientation by emphazing two points which draw perspectives for futur researches.

The first one concerns the relation between the development of temporary organizations (as project teams) and the permanent structures and processes within firms, or more generally society. The relationship between temporary and permanent organizations is classically analysed in a "zero sum game" frame: the question is to find a good compromise between autonomy of temporary organization versus control from permanent logics of the firm. Our findings show that this autonomy/control dilemna is an intermediary step in the projectification process. Beyond that point, temporary organizations does not need less powerfull stable social logics but different ones. Our conclusion is that an important research question in the future is the evolution of the knowledge-oriented permanent organizations (or institutions) coupled with temporary product oriented organizations. Similar results and perspectives can be found at a more macro-level level : specific long term stable social identities or relationship can be positive factors to support the mobility, uncertainty and stress of temporary adventures of innovation projects (see for instance the analysis of the role of institutions in the construction sector by Eccles, 1981).

The second theoretical issue is the learning processes underlying Renault's "projectification". Analysing Japanese firms, Nonaka (1994, p 27-32) proposed a typology of three models for managing the organizational knowledge creation process : Top-down, Middle-Up-Down and Bottom-Up. Our analysis shows how these different models may be associated in a long term transition, as in Renault 30 years projectification. First move in the early 1970's is typical of Top-down logic. Creation of Project Directors at the end of the 1980's inaugurated a Middle- 
Up-Down logic : to generate "creative chaos", by emphasing product development performance as a strategic problem for the firm, and creating new actors and situations (global scope of responsability on a product development) ; to generate involvement and autonomy as conditions to initiate knowledge creation processes in this situation; key role of middle management in the knowledge conversion processes between tacit and explicit knowledge (Nonaka, 1994, p 18-19). Our final comment will be on the implications of such a knowledge creation theory on management research methodology. Different French management and organization research centers have developped since the 1970's longitudinal research methodologies, as demonstrated in our research with Renault on "projectification". Such collaborations, which were exceptional and difficult to arrange in the 1970's, are since the mid-eighties more and more favoured in France, both by professionals and scientific authorities. We propose to interpret this recent development as a result of the growing importance of learning in the "grounded theories" (Glaser and Strauss, 1967) among professionals as much as the impact of the traditional methodological debates within the scientific community.

\section{Acknowledgements.}

The author is particularly grateful for helpful remarks and suggestions given by Rolf A. Lundin to earlier versions of this paper.

\section{References}

Aoki, M., Toward an Economic Model of the Japanese Firm, Journal of Economic Literature (1990), Vol. XXVIII, No. 1, pp.1-27.

Argyris, C. and Schön, D.,Organizational learning (Readings, Mass: Addison-Wesley Publ. Co., 1978).

Banville, E. de and Chanaron, J.J., Vers un système automobile européen, (Towards a European Automobile System), (Paris: CPE-Economica, 1991).

Chandler A.D., Strategy and Structure, (Boston: MIT Press, 1962).

Clark, K.B., Hayes, R.H. Wheelwright, S.C., Dynamic Manufacturing, Creating the Learning Organization, (New York, N Y: The Free Press, 1988).

Clark, K.B., Chew, W. B. and Fujimoto, T., Product Development in the World Auto Industry, (Brooking Papers on Economic Activity, 3:1987).

Clark, K.B. and Fujimoto, T., Product Development Performance : Strategy, Organization and Management in the Auto Industry, (Boston: Harvard Business Press, 1991). 
Clark, K.B. and Wheelwright, S.C., Revolutionizing Product Development: Quantum Leaps in Speed, Efficiency and Quality, (The Free Press, 1992).

Cohendet, P. and Lléréna, P. : Flexibilité et mise en cohérence des données de production; in Les nouvelles rationalisations de la production, (New Trends in Industrial Organization), (Cepadues, Toulouse: Dubois et Terssac Edts,1992), pp. 25 - 41.

Coriat, B. and Taddéi, D., Made in France, L'industrie française dans la concurrence internationale, (Le livre de poche, Hachette, 1993).

Cyert, R.M. and March J.G., A Behavioral Theory of the Firm. (Englewood Cliffs: Prentice Hall, 1963).

Dertouzos, M. L., Robert R. K. and Solow, L.M., Made in America, (Paris: InterEditions, 1990).

Dreyfus, P., La liberté de réussir, (The liberty of succeeding), (Paris: Simoën, 1977).

Eccles, R. G. : The quasi-firm in the construction industry, Journal of Economic Behaviour and Organization, vol 2, pp 335-357.

Galbraith, J. R. : Matrix Organization Design. How to combine functional and Project forms Business Horizons (1971), 14 (1), pp. 29-40.

Gareis, R. Management by project: the management approach for the future, International Journal of Project Management, (1989), Vol. 7, No. 4, pp. 243 - 249.

Giard, V. and Midler, C. (eds), Pilotages des projets et entreprises ; diversités et convergences (Project Management and Firms; Diversity and Convergencies), (Paris: Economica, 1993).

Glaser B. G. and Strauss, A. L., The discovery of Grounded Theory, Strategy for Qualitative Research, (1967), Aldine Publishing Company, Chicago.

Midler, C., L'auto qui n'existait pas, Management des projets et transformation de l'entreprise, (The Car that Did Not Exist. Project Management and Transformations of the Firm), (Paris: InterEditions, 1993 a).

Midler, C., Le responsable de projet, portrait d'un rôle d'influence. (The Project Manager, a role of influence) Gestion 2000 ; Management et prospective , (1993 b), No. 2, April, pp. 123-145.

Mintzberg, H, The Structuring of Organizations. (Englewood Cliffs: Prentice-Hall inc., 1979).

Navarre, C., Pilotage stratégique de la firme et gestion des projets : de Ford et Taylor à Agile et I.M.S., (Strategic management of the firm and project Management : from Ford and Taylor to Agile and I.M.S.) in Giard, V. and Midler, C. (eds): Pilotages des projets et entreprises ; diversités et convergences, pp. $181-215$.

Nonaka, I., Dynamic Theory of Organizational Knowledge Creation, Organization Science, (1994), Vol. 5, No. 1, pp. 14-37. 
Sayles L. and Chandler, M., The Project Manager: Organizational Metronome in Managing Large Systems, (New York: Harper \& Row, 1971), pp 204-226.

Stalk G. Jr.and Hout, T.M., Competing against Time, (New York, N Y: The Free Press, 1990).

Thompson, J.D., Organizations in Action, (McGraw Hill, 1967).

Womack, J.P., Jones, D.T., Roos, D. and Carpenter, D.S., The Machine That Changed the World, (Macmillan, 1990). 